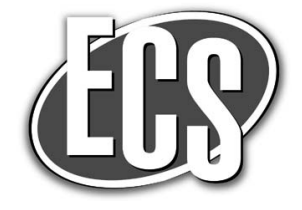

\title{
Composite Electrodes Made from Carbon Cloth as Supercapacitor Material and Manganese and Cobalt Oxide as Battery One
}

\author{
I. Aldama, ${ }^{a}$ V. Barranco, ${ }^{a}$ T. A. Centeno, ${ }^{b}$ J. Ibañez, ${ }^{c, *}$ and J. M. Rojo ${ }^{a, z}$ \\ ${ }^{a}$ Instituto de Ciencia de Materiales de Madrid (ICMM), Consejo Superior de Investigaciones Cientificas (CSIC), \\ Cantoblanco, 28049 Madrid, Spain \\ ${ }^{b}$ Instituto Nacional del Carbon (INCAR), CSIC, 33080 Oviedo, Spain \\ ${ }^{c}$ Centro Nacional de Investigaciones Metalurgicas (CENIM), CSIC, 28040 Madrid, Spain
}

\begin{abstract}
Mn oxide and/or Co oxide are deposited on flexible carbon cloth by a cathodic potentiodynamic procedure from their respective sulfates. In $\mathrm{KOH}$ electrolyte, the charge stored from reversible redox reactions of the two oxides (battery response) overlaps with the charge stored from the double layer of the carbon cloth (supercapacitor response). These charges or capacities are compared. For the electrodes having one oxide only, either $\mathrm{Mn}$ or Co oxide, the highest capacity is obtained for $8 \mathrm{wt} \%$ oxide load. To overcome this limitation, both $\mathrm{Mn}$ and Co oxide are simultaneously or sequentially electrodeposited on carbon cloth over a broad compositional range. The electrode capacity can reach $71 \mathrm{~mA} \cdot \mathrm{h} \cdot \mathrm{g}^{-1}$ or $0.9 \mathrm{~mA} \cdot \mathrm{h} \cdot \mathrm{cm}^{-2}$, which are higher than the values found for the bare carbon cloth. The electrode capacity depends on the relative content of the carbon cloth and the two deposited oxides according to the rule of mixtures. The decrease of the specific surface area of the carbon cloth is discussed in relation to the deposited oxide. The high capacity retention vs current is due to the contribution of the carbon cloth substrate. The electrode cycle life is discussed on the basis of the supercapacitor response and battery one.

(C) The Author(s) 2016. Published by ECS. This is an open access article distributed under the terms of the Creative Commons Attribution 4.0 License (CC BY, http://creativecommons.org/licenses/by/4.0/), which permits unrestricted reuse of the work in any medium, provided the original work is properly cited. [DOI: 10.1149/2.1061605jes] All rights reserved.
\end{abstract}

Manuscript submitted December 7, 2015; revised manuscript received February 3, 2016. Published February 12, 2016.

Amorphous manganese oxide, usually so-called as $\mathrm{MnO}_{2} \cdot \mathrm{xH}_{2} \mathrm{O}$, is an electrode material for supercapacitors that show moderate specific capacitance and moderate capacitance retention on current and cyclability as compared with amorphous ruthenium oxide $\left(\mathrm{RuO}_{2} \cdot \mathrm{xH}_{2} \mathrm{O}\right)$. However, $\mathrm{MnO}_{2} \cdot \mathrm{xH}_{2} \mathrm{O}$ is cheaper and environmentally friendly, and both features have encouraged the research on this oxide. $^{1-11}$ The main drawbacks seem to be its reduced electrical conductivity, $10^{-6}-10^{-5} \mathrm{~S} \mathrm{~cm}^{-1}$, and the difficulty of the electrolyte to access the interior of big oxide particles. ${ }^{2,3}$ To overcome these, smaller particles of the oxide can be deposited on a conducting material acting as scaffold or substrate. The open framework of the scaffold not only provides mechanical support, also collects electrons from the collector to the oxide particles and favors the access of the electrolyte to the oxide particles. If the scaffold is made from a carbonaceous material or any other active electrode material, it can provide a capacitance in addition to the capacitance of the deposited oxide. ${ }^{12-25}$

The preparation of $\mathrm{MnO}_{2} \cdot \mathrm{xH}_{2} \mathrm{O}$ by a chemical route, usually from $\mathrm{KMnO}_{4}$, involves reduction "in situ" of $\mathrm{Mn}^{7+}$ to $\mathrm{Mn}^{4+}$ which can be favored by the presence of carbon. ${ }^{1-25}$ The preparation by an electrochemical route has been tried from several $\mathrm{Mn}$ precursors, e.g. aqueous solutions of $\mathrm{Mn}\left(\mathrm{CH}_{3} \mathrm{COO}\right)_{2}, \mathrm{Mn}\left(\mathrm{NO}_{3}\right)_{2}, \mathrm{MnCl}_{2}$ or $\mathrm{Mn}_{2} \mathrm{SO}_{4}$. The electrodeposition involves oxidation of $\mathrm{Mn}^{2+}$ to $\mathrm{Mn}^{4+}$ and several procedures (potentiostatic, potentiodynamic or galvanostatic) have been tried. ${ }^{26-41}$ The electrodes prepared by the chemical or electrochemical route showed specific capacitances in the range 150-300 F/g and oxide loadings up to $30 \mathrm{wt} \%$. The choice of the electrolyte, either neutral o basic, is another important parameter that also affects both the charge stored and the voltage window. ${ }^{30}$ While $\mathrm{MnO}_{2} \cdot \mathrm{xH}_{2} \mathrm{O}$ in neutral electrolytes shows a capacitor behavior (pseudocapacitor) ${ }^{1-3}$ the oxide in basic electrolytes shows a battery behavior. ${ }^{30}$

$\mathrm{Co}$ oxide, usually identified as the spinel $\mathrm{Co}_{3} \mathrm{O}_{4}$, has been considered as another active electrode material for supercapacitors since the pioneer works ${ }^{42,43}$ despite its electrochemical response in $\mathrm{KOH}$ electrolyte is dominated by a battery behavior. ${ }^{44}$ This compound is a p-type semiconductor and shows an electrical conductivity of the order of $10^{-3} \mathrm{~S} \mathrm{~cm}^{-1},{ }^{45}$ which is much higher than the electrical conductivity of $\mathrm{MnO}_{2} \cdot \mathrm{xH}_{2} \mathrm{O} .{ }^{3}$ The Co oxide has been prepared by chemical $^{43,47-52}$ or electrochemical route ${ }^{42,53-63}$ on several substrates, usually metallic substrates. Regarding the two oxides together, there

\footnotetext{
*Electrochemical Society Member.
}

${ }^{\mathrm{z}}$ E-mail: jmrojo@icmm.csic.es are only a few works ${ }^{64-68}$ in which Co oxide and Mn one were electrodeposited on several substrates (stainless steel, graphite, ITO, gold or nickel foil), which are different from the carbon cloth chosen in this work. In those works, the two oxides were electrodeposited from other precursors (chlorides or acetates) and by procedures (anodic potentiostatic, anodic galvanostatic or pulsed galvanostatic procedure) that are different from the potentiodynamic procedure chosen in this work. Moreover, their electrochemical behavior as electrodes was examined in $\mathrm{Na}_{2} \mathrm{SO}_{4}$ electrolyte ${ }^{64-67}$ with the exception of one case dealing with $\mathrm{KOH}$ electrolyte. ${ }^{68}$ Therefore, substrate, precursor, electrodeposition procedure, oxide loading and electrolyte were different from those reported in this work.

Looking at the carbon fabric or carbon cloth (CC), which is a flexible material acting as scaffold or substrate in this work, it has been scarcely used as support for electrodeposition of oxides; only one work for the $\mathrm{MnO}_{2} \cdot \mathrm{xH}_{2} \mathrm{O},{ }^{34}$ other for $\mathrm{Co}_{3} \mathrm{O}_{4}{ }^{63}$ and another one for $\mathrm{RuO}_{2} \cdot \mathrm{xH}_{2} \mathrm{O}^{69}$ are reported as far as we know.

The aim of this work is to study the effect of the deposited Mn and/or Co oxide on the charge or capacity of the electrodes. The limitation in capacity of electrodes having one oxide only is overcome by depositing two oxides. They are simultaneously or sequentially electrodeposited on carbon cloth. The work also analyzes the synergy of the two deposited oxides and the carbon cloth on the capacity, capacity retention vs. current density and cycle life.

\section{Experimental}

The material used as scaffold or substrate is an activated carbon cloth (CC) of $0.57 \mathrm{~mm}$ thick (Figure 1a) manufactured by Carbongen SA. As illustrated by Figure $1 \mathrm{~b}, \mathrm{CC}$ is made from woven bundles of carbon fibers, each fiber of 6-7 $\mu \mathrm{m}$ in diameter. Circular pieces of $12 \mathrm{~mm}$ in diameter and $12 \mathrm{mg}$ in weight were punched out (Figure 1c). The specific surface area of $1100 \mathrm{~m}^{2} \mathrm{~g}^{-1}$ derives from the presence of micropores with an average size of $1.7 \mathrm{~nm}$ and mesopores below $3-4 \mathrm{~nm}$. The electrical conductivity is $0.15 \mathrm{~S} \mathrm{~cm}^{-1}$; the circular pieces showed a resistance of $0.3 \mathrm{ohm}$ in the perpendicular direction to the circle.

The porosity of the pristine carbon cloth and the oxide-deposited samples was studied by $\mathrm{N}_{2}$ adsorption at $77 \mathrm{~K}$ (Micromeritics ASAP 2010). The specific surface area was estimated by the analysis of the isotherm by the BET equation and the comparison plot (Vulcan 3G as reference). In the case of the pristine cloth, immersion calorimetry into $0.4 \mathrm{M}$ aqueous solution of phenol was also used. The average 

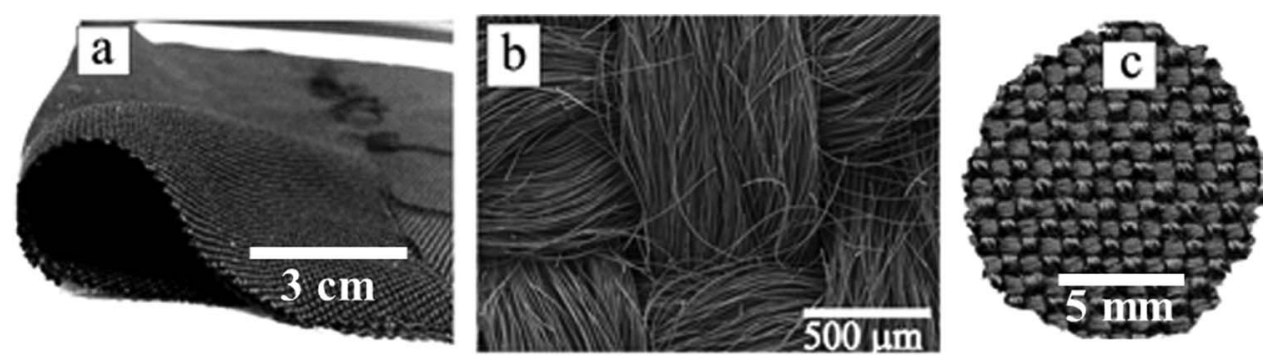

Figure 1. Picture of the flexible carbon cloth (a). Magnification of the picture (b). A circular piece of the carbon cloth used as substrate for the electrodeposition of Mn and/or Co oxide (c).

micropore size was determined by using Dubinin-Radushkevich equation whereas the mesopore size distribution was calculated by means of the Kruk-Jaroniec-Sayari method.

Electrodeposition of Mn oxide and/or Co one on circular pieces of $\mathrm{CC}$ was carried out by cyclic voltammetry (potentiodynamic procedure) in a three-electrode cell. The oxide precursor was $0.1 \mathrm{M}$ aqueous solutions of $\mathrm{MnSO}_{4} \cdot 4 \mathrm{H}_{2} \mathrm{O}$ and/or $\mathrm{CoSO}_{4} \cdot 6 \mathrm{H}_{2} \mathrm{O}$ (reagent grade from Sigma-Aldrich). The volume of each sulfate solution was $4.5 \mathrm{ml}$ per piece of CC. When both solutions were blended, the volume of each solution was half, $2.25 \mathrm{ml}$. Before each electrodeposition, the CC piece was in contact with the sulfate solution under primary vacuum ( 0.1 Torr) for $30 \mathrm{~min}$. The $\mathrm{CC}$ piece was the working electrode, a gold wire was the counter electrode and $\mathrm{Ag} / \mathrm{AgCl}$ was the reference electrode. Each electrodeposition was performed from the open circuit potential (OCP) to $-0.8 \mathrm{~V}$ and then from $-0.8 \mathrm{~V}$ to OCP, both at a voltage scan rate of $0.5 \mathrm{mV} \mathrm{s}^{-1}$. The OCP was $0.35 \mathrm{~V}$ for the Co sulfate solution, $0.30 \mathrm{~V}$ for the Mn sulfate solution and $0.32 \mathrm{~V}$ for the blended Co and Mn sulfate solution (1/1 volume ratio). Three samples were prepared after one electrodeposition cycle:

(i) Mn oxide electrodeposited on CC (labelled as Mn sample)

(ii) Co oxide electrodeposited on CC (Co sample)

(iii) $\mathrm{Mn}$ and Co oxide simultaneously electrodeposited on $\mathrm{CC}$ from a blend solution of $\mathrm{Mn}$ sulfate and $\mathrm{Co}$ one (MnCo 50 sample)

Two samples were prepared after two consecutive cycles:

(iv) first the Mn oxide and then the Co oxide (MnCo sample)

(v) first the Co oxide and then the Mn oxide (CoMn sample).

Furthermore, four samples having one oxide only, the Mn oxide or the Co one, but higher oxide contents than the Mn sample and the $\mathrm{Co}$ sample were obtained by electrodeposition after three or six accumulative cycles. These four samples are labelled as Mn 3cy, Mn 6cy, Co 3 cy and Co 6cy.

Once the electrodeposition was over, the samples were taken out from the cell, washed in distilled water and dried at $120^{\circ} \mathrm{C}$ for $2 \mathrm{~h}$ in still air. The load of the deposited oxide was deduced from the difference of weights of the electrodeposited samples and the bare carbon cloth.

The resulting samples were electrochemically characterized as electrodes in a three-electrode cell. They were the working electrode whereas a platinum wire was the counter electrode and $\mathrm{Hg} / \mathrm{HgO}$ was the reference electrode. The electrolyte was $1 \mathrm{M} \mathrm{KOH}$ aqueous solution; this electrolyte was chosen because Co oxide and $\mathrm{Mn}$ one are stable in it. Cyclic voltammetries were recorded in the voltage range from -0.8 to $0.2 \mathrm{~V}$ vs. $\mathrm{Hg} / \mathrm{HgO}$ by applying a voltage scan rate of $0.5-50 \mathrm{mV} \mathrm{s}^{-1}$. Galvanostatic measurements were carried out in the same voltage range at current densities of $1-26 \mathrm{~mA} \mathrm{~cm}^{-2}$. Cycle life was checked in two-electrode Swagelok-type cell at $26 \mathrm{~mA} \mathrm{~cm}^{-2}$. For that two equal electrodes of $12 \mathrm{~mm}$ in diameter were separated by a glassy microfiber paper Whatman $934 \mathrm{AH}$.

Microstructural characterization of the oxide-deposited samples was carried out by scanning electron microscopy (SEM). Images were obtained in the secondary electron mode by a FEG HITACHI S-4800 instrument. Measurements of Energy Dispersive X-ray Spectrometer
(EDS) were carried out to determine the relative content of Mn and $\mathrm{Co}$ in the samples having both the $\mathrm{Mn}$ oxide and the Co one on the CC.

X-ray photoelectron spectroscopy (XPS) was performed using a Fisons MT500 spectrometer equipped with a hemispherical electron analyzer (CLAM 2) and Mg K $\alpha$ X-ray source operating at $300 \mathrm{~W}$. The samples were attached to a conductive double side tape and fixed on small flat discs supported by an XYZ manipulator. The pressure was below $10^{-8}$ Torr during data acquisition and the take-off angle was $90^{\circ}$ with respect to the surface sample. The spectra were collected for 20-90 min, depending on the peak intensities at pass energy of $20 \mathrm{eV}$, which is typical of high-resolution conditions. The intensities were estimated through the peak areas after smoothing and subtraction of the S-shaped background and fitting the experimental curves to a mix of Lorentzian and Gaussian lines of variable proportions. Accurate binding energies (BE) could be determined by referencing to the $\mathrm{C} 1 \mathrm{~s}$ peak at $285.0 \mathrm{eV}$. Atomic ratios were computed from peak intensity ratios and reported atomic sensitivity factors.

\section{Results and Discussion}

The cyclic voltammetries (CVs) of the oxide-deposited samples in $\mathrm{KOH}$ electrolyte are shown in Figure 2a. For comparison, the CV of the bare $\mathrm{CC}$ is also included. It shows a nearly rectangular shape from -0.8 to $0.1 \mathrm{~V}$ vs. $\mathrm{Hg} / \mathrm{HgO}$ that can be ascribed to a response of electrochemical double layer capacitor; the low intense and very broad peak at ca. $-0.4 \mathrm{~V}$ suggests a pseudo capacitance in addition to the double layer capacitance. The CV of the Mn sample shows two oxidation peaks in charge, at ca. -0.25 and $0 \mathrm{~V}$, and two reduction peaks in discharge, at ca. -0.35 and $-0.05 \mathrm{~V}$ (see black arrows in Fig. 2a). These peaks, which are ascribed to $\mathrm{Mn}^{3+}-\mathrm{Mn}^{4+}$ redox reactions in $1 \mathrm{M}$ $\mathrm{KOH}$ electrolyte, ${ }^{26,30}$ differs from the nearly rectangular $\mathrm{CV}$ of the $\mathrm{Mn}$ oxide in $\mathrm{Na}_{2} \mathrm{SO}_{4}$ electrolyte. ${ }^{2,3}$ The $\mathrm{CV}$ of the Co sample shows one oxidation peak at ca. $0.05 \mathrm{~V}$ and one reduction peak at ca. $-0.4 \mathrm{~V}$ (see green arrows in Fig. 2a). It has been reported that $\mathrm{Co}(\mathrm{OH})_{2}$ and $\mathrm{Co}_{3} \mathrm{O}_{4}$ shows two anodic peaks and two cathodic ones, which seems to be associated with $\mathrm{Co}^{2+}-\mathrm{Co}^{3+}$ and $\mathrm{Co}^{3+}-\mathrm{Co}^{4+}$ in $\mathrm{KOH}$ electrolyte. One peak at a voltage close to that observed in our sample, the other peak at higher voltage, ca. $0.3-0.4 \mathrm{~V}^{43,58-60,63}$ Looking for the latter redox peak, the CV was extended to higher voltages but decomposition of water above $0.2 \mathrm{~V}$ prevented us the observation of this high voltage peak. The $\mathrm{CV}$ of the samples having the two oxides (samples MnCo50, MnCo and CoMn) show two redox peaks coming up from the two redox peaks of Mn oxide and the one redox peak of Co oxide, the latter overlapping with one of the Mn oxide peak.

The dependence of the intensity vs. the voltage scan rate has been analyzed at voltages where redox peaks appear and also where redox peaks do not appear in the CVs. It is known that $I=\mathrm{a} \cdot v^{\mathrm{b}}$, where $I$ is the intensity, $v$ is the voltage scan rate and " $a$ " and " $b$ " are two parameters. The parameter " $b$ " takes the value of 0.5 for a battery and the value of 1 for a supercapacitor, either electrochemical double-layer capacitor or pseudocapacitor. ${ }^{70}$ As an example, the dependence of $\log _{10} I$ vs. $\log _{10} v$ at three voltages, i.e. at $-0.6 \mathrm{~V}$ and at the voltage of two peaks, has been checked for the CoMn sample in the anodic scan 

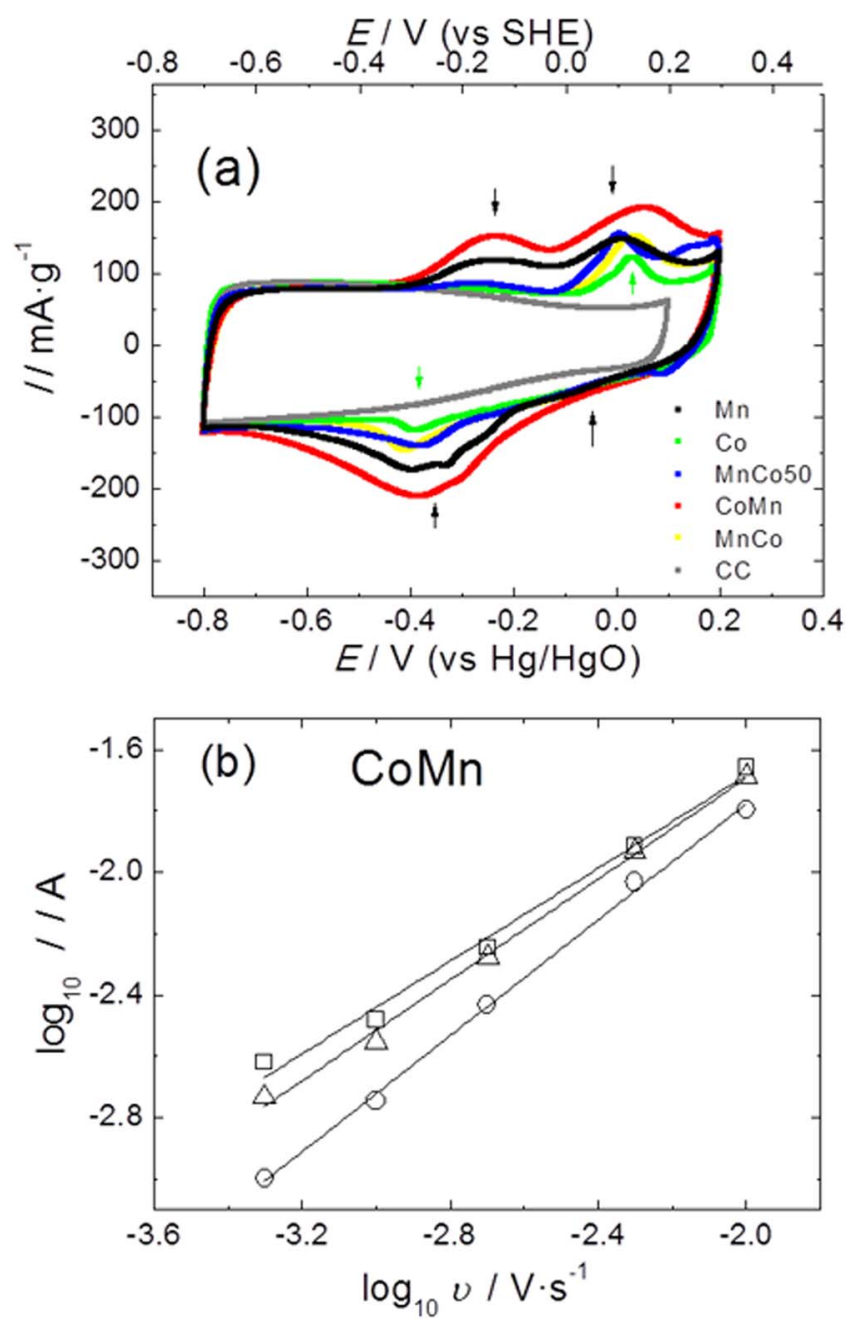

Figure 2. (a) Cyclic voltammetries obtained at $0.5 \mathrm{mV} \mathrm{s}^{-1}$ for the oxidedeposited samples and the bare carbon cloth $(\mathrm{CC})$. Voltages are referred to the $\mathrm{Hg} / \mathrm{HgO}$ electrode (down axis) and also to the standard hydrogen electrode, SHE (up axis). (b) Dependence of intensity vs. voltage scan rate measured at the voltages of $-0.6 \mathrm{~V}$ (circles), $-0.2 \mathrm{~V}$ (triangles), and $0.06 \mathrm{~V}$ (squares) vs. $\mathrm{Hg} / \mathrm{HgO}$ for the CoMn sample. Straight lines are the best fittings.

(Figure 2b). At the former voltage, the parameter " $b$ " is equal to $0.95 \pm 0.02$, which agrees with the dominant supercapacitor response of the CC substrate. At the voltage of the two peaks, "b" takes the value of $0.82 \pm 0.03$ and $0.76 \pm 0.04$; these values are intermediate between those obtained for a battery and a supercapacitor (either electrochemical double-layer capacitor or pseudocapacitor) pointing out that there are two contributions, the supercapacitor response due to the $\mathrm{CC}$ substrate and the battery response due to the deposited $\mathrm{Mn}$ oxide and Co one.

Both the shape of the CVs and the kinetic study point out that the electrochemical response of the oxide-deposited samples results from coupling the supercapacitor response of the CC substrate with the battery response of the deposited oxides. The two responses can be compared on the basis of their charge or capacity; however, they cannot be compared in terms of capacitance in agreement with that reported in Reference 44 . The specific charge or capacity $(Q)$ was determined by integrating the CVs in the total voltage range according to:

$$
Q=\int I \cdot \mathrm{d} V / 2 \cdot v \cdot m
$$

where $I$ is the current, $V$ is the voltage, $v$ is the voltage scan rate and $m$ is the electrode weight. The term 2 comes from the fact that the integrations done involved both the anodic and cathodic scan. Table I

\begin{tabular}{|c|c|c|c|c|}
\hline Sample & $\begin{array}{c}\text { ANEM } \\
\left(\mathrm{mg} \cdot \mathrm{cm}^{-2}\right)\end{array}$ & $\begin{array}{l}\text { Oxide mass } \\
(\%)\end{array}$ & $\begin{array}{l}\text { Oxide mass } \\
\left(\mathrm{mg} \cdot \mathrm{cm}^{-2}\right)\end{array}$ & $\underset{\left(\mathrm{mA} \cdot \mathrm{h} \cdot \mathrm{g}^{-1}\right)}{Q}$ \\
\hline $\mathrm{CC}$ & 9.5 & - & - & 32 \\
\hline $\mathrm{Mn}$ & 11.0 & 8.2 & 0.9 & 56 \\
\hline Co & 10.8 & 7.4 & 0.8 & 46 \\
\hline $\mathrm{MnCo} 50$ & 10.9 & 7.3 & 0.8 & 51 \\
\hline $\mathrm{MnCo}$ & 12.1 & 8.8 & 1.07 & 49 \\
\hline CoMn & 12.4 & 12 & 1.49 & 67 \\
\hline
\end{tabular}

compares the specific charge or capacity of the bare CC sample with that of the oxide-deposited samples. The specific capacity of the latter samples is 1.4-2 times the specific capacity of the bare CC, showing the significant contribution of the deposited oxides to increase the electrode capacity. The slight increase in the total voltage window, from 0.9 to $1 \mathrm{~V}$, also results from overlapping the supercapacitor response of the $\mathrm{CC}$ and the battery response of the two oxides.

The galvanostatic plots (GCs) obtained at low current density $\left(1 \mathrm{~mA} \mathrm{~cm}^{-2}\right)$ are shown in Figure 3 . For the oxide-deposited samples they show a distorted triangular shape coming up from overlapping the supercapacitor response and the battery one. From the GCs plots, the specific capacity was determined in discharge according to the equation:

$$
Q=I \cdot t_{d} / m
$$

where $I$ is the current applied, $t_{d}$ is the time during the discharge and $m$ is the weight of the electrode (CC plus oxide). The GCs plots were also obtained at higher current densities, i.e. $>1 \mathrm{~mA} \mathrm{~cm}^{-2}$; some GCs for the CoMn sample are shown in Figure $4 \mathrm{a}$ as examples. They show the distorted triangular shape already discussed. The dependence of the specific capacity as a function of the current density is shown in Figure $4 \mathrm{~b}$. At low current densities the capacity is higher for the oxidedeposited samples than for the CC sample. It shows the significant contribution of the deposited oxides to increase the electrode capacity, and hence the energy. As the current density increases the capacity of the oxide-deposited samples is close to that of the CC sample. It shows that at high current densities the electrode capacity, and also the power, is dominated by the contribution of the CC substrate.

$\mathrm{X}$-ray diffraction patterns do not provide any additional information on the electrodeposited $\mathrm{Mn}$ and/or Co oxide. Probably, the amorphous feature of the deposited oxides and their low content (8-14 $\mathrm{wt} \%$ ) account for the lack of information of this technique. The X-ray diffraction patterns of all the oxide-deposited samples are nearly the same as the pattern of the bare CC (Figure S1).

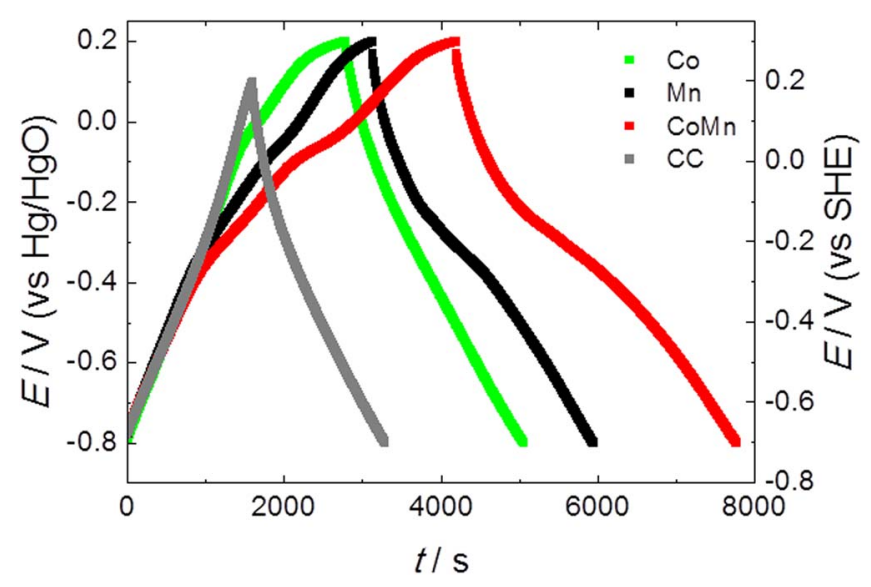

Figure 3. Galvanostatic plots recorded at $1 \mathrm{~mA} \mathrm{~cm}{ }^{-2}$ for the oxide-deposited samples and the bare carbon cloth (CC). 

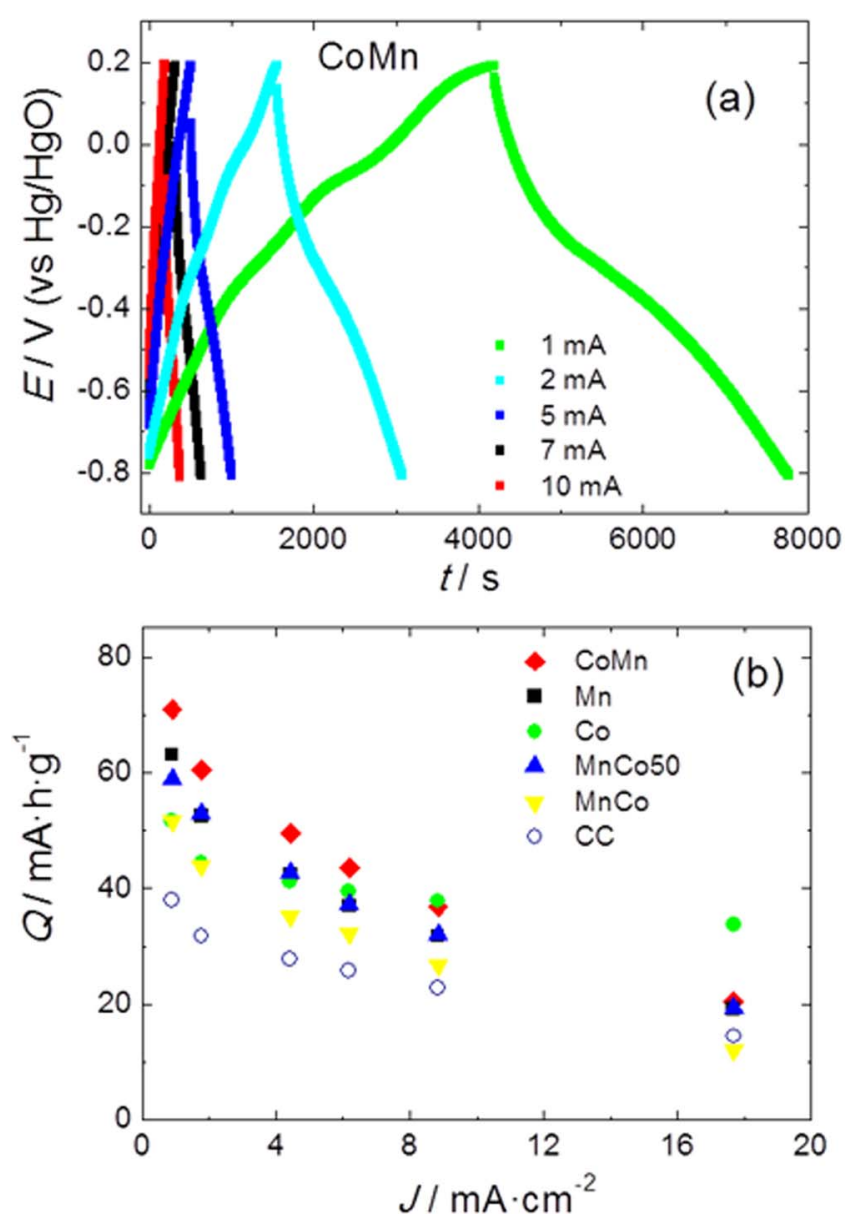

Figure 4. (a) Galvanostatic plots obtained at several currents on the CoMn sample. (b) Dependence of the specific capacity as a function of the current density for the oxide-deposited samples and the bare carbon cloth (CC).

SEM pictures of the samples Co, Mn, and CoMn are shown as examples in Figure 5. In the Co sample, the deposited Co oxide appears uniformly distributed on the carbon fibers (Fig. 5a). Interconnected flakes or sheets of the Co oxide give rise to round aggregates of two sizes, 0.3 and $5 \mu \mathrm{m}$ in diameter (inset of Fig. 5a). The bigger aggregates show flakes or sheets of ca. $700 \mathrm{~nm}$ in length and ca. 20 $\mathrm{nm}$ in thickness. The smaller aggregates show flakes or sheets of ca. $70 \mathrm{~nm}$ in length and ca. $7 \mathrm{~nm}$ in thickness. The shape and size of the deposited aggregates agree with that reported for $\mathrm{Co}_{3} \mathrm{O}_{4}$ on other substrates. ${ }^{48,50,54,55,57-63}$ In contrast, the Mn sample shows that the deposited Mn oxide is heterogeneously distributed on the carbon fibers (Figure 5b). Big aggregates of this oxide with sizes up to $100 \mu \mathrm{m}$ are observed. A detailed inspection of these aggregates show that they are made up from flakes or sheets having a thickness of ca. $20 \mathrm{~nm}$ and a length of ca. $1 \mu \mathrm{m}$ (inset of Fig. 5b). The sizes of these aggregates, especially the lengths, are larger than those reported for this oxide on another carbon cloth, in which the oxide was electrodeposited from the same precursor (manganese sulfate solution) but by a different procedure, a galvanostatic anodic procedure. ${ }^{34}$ Hence, the size (and also the shape) of the deposited Mn oxide is affected by the electrodeposition chosen. The SEM picture of the CoMn sample shows that the two oxides are placed on the carbon fibers (Figure 5c). A magnification of this picture (inset of Fig. 5c) shows aggregates like the ones observed in Figures $5 \mathrm{a}$ and $5 \mathrm{~b}$. The same kinds of aggregates are observed for the samples MnCo50 and MnCo. In all samples the aggregates of Co oxide and $\mathrm{Mn}$ one show voids, of $50-500 \mathrm{~nm}$ in size, which can favor the access of the electrolyte to the inner part of the deposited oxides and also to the surface of the carbon fibers. An analysis by EDS showed that the electrolyte not only accessed to the
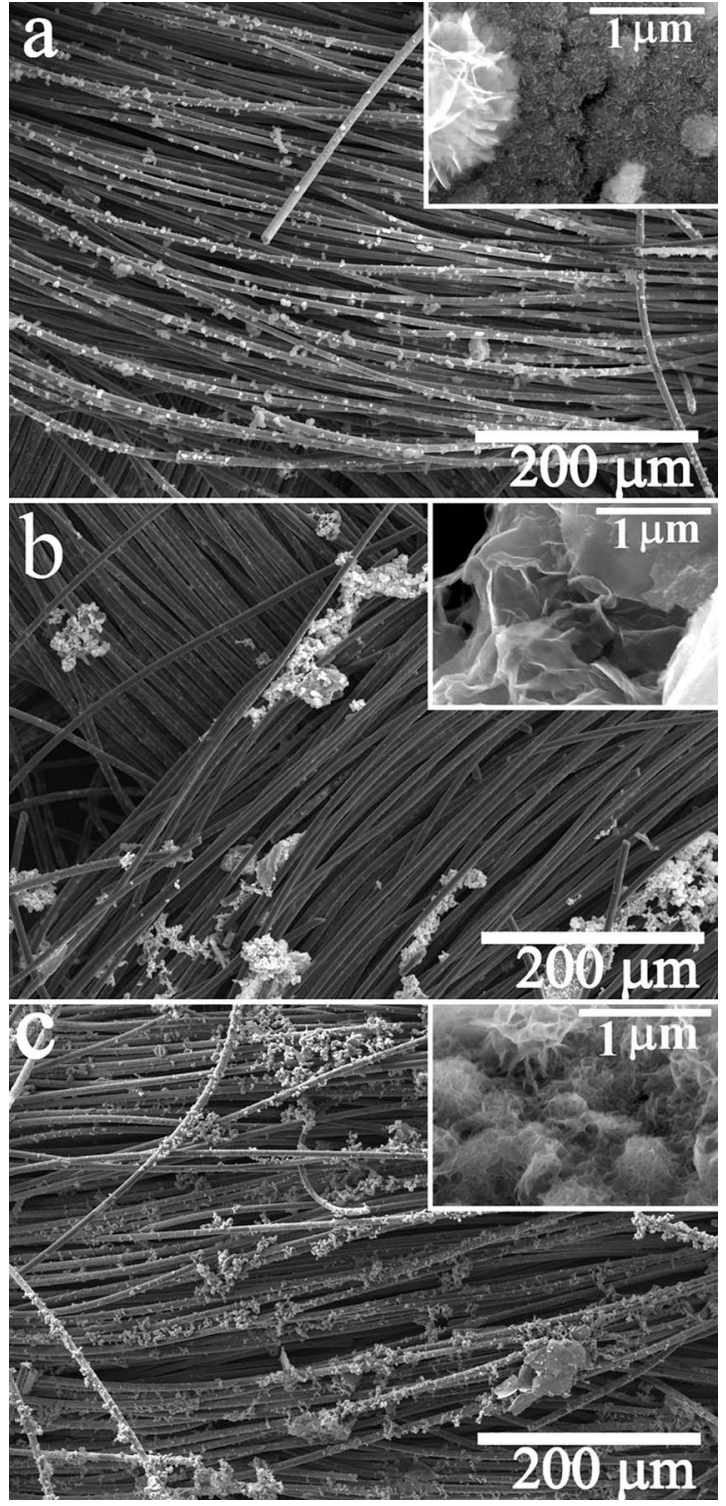

Figure 5. SEM pictures of the Co sample (a), Mn sample (b) and CoMn sample (c). The insets show magnified pictures.

oxide aggregates and the outer part of the carbon fibers but also to the inner part of these fibers. The EDS analysis also provided the $\mathrm{Mn} / \mathrm{Co}$ ratio for the samples having the two oxides. This ratio is $0.3 / 0.7$ for the MnCo50 sample, 0.1/0.9 for the MnCo sample and 0.5/0.5 for the CoMn one. These values are different from the ones reported in previous works, in which the Mn oxide content was always higher than the Co oxide one. ${ }^{64,65,67,68}$

The results obtained from the $\mathrm{Mn}_{2 \mathrm{p}}$ and $\mathrm{Co}_{2 \mathrm{p}}$ high resolution XPS peaks on the outer surface ( $<3 \mathrm{~nm}$ thick) are shown in Table II. For the MnCo50 sample, the Co atomic percentage is higher than the Mn one; it confirms the preferential deposition of the Co oxide against the $\mathrm{Mn}$ one despite they were simultaneously electrodeposited. For the $\mathrm{MnCo}$ sample, the Co content is higher than the Mn one, which is negligible; it suggests that the Mn oxide electrodeposited in the first cycle was removed in the second one in which Co oxide was electrodeposited. For the CoMn sample, the content of the two oxides is nearly equal. Hence, the information about Mn/Co ratio deduced from XPS agrees with that deduced from EDS.

The high-resolution $\mathrm{Mn}_{2 \mathrm{p}}$ XPS spectra of the samples $\mathrm{Mn}$, MnCo50 and CoMn are similar (Figure S2); they show a Mn $2 \mathrm{p}_{3 / 2}$ signal at a binding energy of $641.7 \mathrm{eV}$, which is associated with the 


\begin{tabular}{|c|c|c|c|c|c|}
\hline \multicolumn{6}{|c|}{$\begin{array}{l}\text { Table II. Atomic percentages determined from the } \mathrm{C}_{1 \mathrm{~s}}, \mathrm{O}_{1 \mathrm{~s}}, \mathrm{Mn}_{2 \mathrm{p}} \\
\text { and } \mathrm{Co}_{2 \mathrm{p}} \text { high resolution peaks on the outer surface }(<3 \mathrm{~nm} \\
\text { in thickness) for the bare carbon cloth (CC) and the oxide- } \\
\text { electrodeposited samples. }\end{array}$} \\
\hline Sample & $\begin{array}{c}\mathrm{C} \\
\text { (at. \%) }\end{array}$ & $\begin{array}{c}\mathrm{O} \\
\text { (at. \%) }\end{array}$ & $\begin{array}{c}\mathrm{Mn} \\
\text { (at. \%) }\end{array}$ & $\begin{array}{c}\text { Co } \\
\text { (at. \%) }\end{array}$ & $\begin{array}{l}\mathrm{C} / \mathrm{O} \text { atomic } \\
\text { ratio }\end{array}$ \\
\hline $\mathrm{CC}$ & 77.5 & 22.5 & - & - & 3.4 \\
\hline $\mathrm{Mn}$ & 60.5 & 35.0 & 5.0 & - & 1.7 \\
\hline $\mathrm{Co}$ & 52.6 & 42.0 & - & 5.3 & 1.3 \\
\hline $\mathrm{MnCo} 50$ & 49.4 & 39.2 & 4.2 & 7.2 & 1.3 \\
\hline $\mathrm{MnCo}$ & 52.2 & 41.3 & 0.0 & 6.5 & 1.3 \\
\hline CoMn & 44.3 & 48.3 & 4.0 & 5.0 & 0.9 \\
\hline
\end{tabular}

presence of manganese (III) oxy-hydroxide. ${ }^{71}$ The quantitative analysis of the high-resolution $\mathrm{O}_{1 \mathrm{~s}}$ peak associated with $\mathrm{Mn}$ is consistent with $\mathrm{MnOOH}$ and also with $\mathrm{MnO}_{2}$. Bearing in mind the large size of the Mn oxide aggregates and the fact that only the surface is analyzed by XPS, presumably the outer part of the aggregates is made from $\mathrm{MnOOH}$ while the inner part is $\mathrm{MnO}_{2}$. The $\mathrm{Co}_{2 p}$ spectra of the samples Co, MnCo50, MnCo and CoMn are rather similar (Figure $\mathrm{S} 2$ ); they consist of a Co $2 \mathrm{p}_{3 / 2}$ signal at a binding energy of $780.3 \mathrm{eV}$, which is associated with the presence of Co (III) ${ }^{72,73}$ The quantitative analysis of the $\mathrm{O}_{1 \mathrm{~s}}$ peak associated with Co agrees with the presence of $\mathrm{CoOOH}$ or $\mathrm{Co}(\mathrm{OH})_{2}$ in the outer part of the aggregates and $\mathrm{Co}_{3} \mathrm{O}_{4}$ in the inner part. The oxygen atomic percentage of the oxide-deposited samples $(>35 \%)$ is higher than that of bare CC (22.5\%) (Table II); it suggests that the Mn oxide and/or Co one are attached to the carbon fibers through oxygen bonding. The highest oxygen percentage is found for the CoMn sample, which also shows the highest specific capacity at low current densities (Figure $4 b$ ).

The specific capacity of the electrodes measured at $1 \mathrm{~mA} \mathrm{~cm}^{-2}$, i.e. $Q_{1}$, is plotted vs. the oxide load in Figure 6. For the samples having only the $\mathrm{Mn}$ oxide deposited on the $\mathrm{CC}$, two regimes are observed: regime $\mathrm{A}$ in which $Q_{1}$ increases as the oxide content does, and regime $\mathrm{B}$ in which $Q_{1}$ is nearly constant. For the samples having only the Co oxide deposited on the $\mathrm{CC}$, the two regimes are also observed. In the two series there is a crossover at ca. $8 \mathrm{wt} \%$.

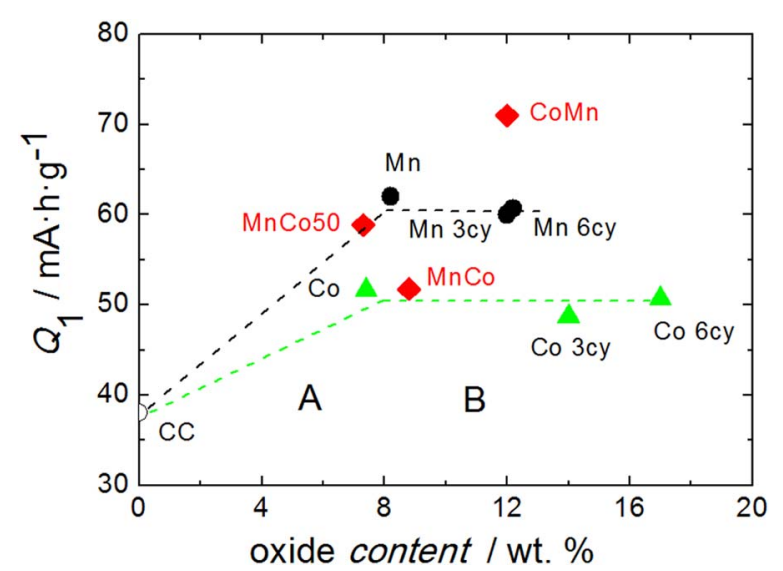

Figure 6. Variation of the specific capacity measured at $1 \mathrm{~mA} \mathrm{~cm}^{-2}$ vs. the oxide load. Dashed lines are a guide to the eye for the two regimes, A and B.

Assuming that the experimental $Q_{1}$ values hold the equation:

$$
\left.Q_{1}=\text { [oxide content } \cdot Q_{\text {loxide }}+(100 \text {-oxide content }) \cdot Q_{1 C C}\right] / 100
$$

where $Q_{1 C C}$ is equal to $38 \mathrm{~mA} \cdot \mathrm{h} \cdot \mathrm{g}^{-1}$ and the oxide contents are those shown in Figure 6 and Table III, the specific capacity of the deposited oxide, $Q_{1 \text { oxide }}$, can be estimated. For the samples having $\mathrm{Mn}$ oxide only, the $Q_{1 \text { oxide }}$ takes the value of $331 \mathrm{~mA} \cdot \mathrm{h} \cdot \mathrm{g}^{-1}$ for the oxide content up to $8 \mathrm{wt} \%$ but a lower value of $221 \mathrm{~mA} \cdot \mathrm{h} \cdot \mathrm{g}^{-1}$ for $12 \mathrm{wt} \%$ and $227 \mathrm{~mA} \cdot \mathrm{h} \cdot \mathrm{g}^{-1}$ for $12.2 \mathrm{wt} \%$. The same happens for the samples having Co oxide only. The $Q_{\text {loxide }}$ takes the value of $227 \mathrm{~mA} \cdot \mathrm{h} \cdot \mathrm{g}^{-1}$ up to $8 \mathrm{wt} \%$ but a lower value of 117 and $114 \mathrm{~mA} \cdot \mathrm{h} \cdot \mathrm{g}^{-1}$ for 14 and $17 \mathrm{wt} \%$, respectively. For the two series of samples, the increase of $Q_{1}$ in regime A is the consequence of the increase in oxide content while keeping the highest $Q_{1 \text { oxide }}$ value for the deposited oxide. The nearly constant value of $Q_{1}$ in regime B appears as compensation between the increase of the oxide content and the decrease of the $Q_{1 \text { oxide }}$ value. For oxide contents below 8 wt $\%$ : (i) the $Q_{1 \text { oxide }}$ value of the deposited $\mathrm{Mn}$ oxide, of $331 \mathrm{~mA} \cdot \mathrm{h} \cdot \mathrm{g}^{-1}$, is close to the theoretical

Table III. Oxide content, experimental specific capacity of the electrodes measured at $1 \mathrm{~mA} \mathrm{~cm}{ }^{-2}\left(Q_{1}\right)$, estimated specific capacity of the deposited oxide $\left(Q_{1 \text { oxide }}\right)$, specific surface area $(S S A)$ referred to the carbon cloth $(C C)$ acting as substrate, specific capacity of the CC substrate estimated from the $S S A\left(Q_{1 C C}\right)$, estimated specific capacity of the deposited oxide $\left(Q_{1 o x}\right)$ considering the decrease of the $S S A, \mathrm{Mn} / \mathrm{Co}$ atomic ratio $(\mathrm{Mn} / \mathrm{Co}$ ratio), estimated specific capacity of the samples having the two oxides $\left(Q_{1 \text { estimated }}\right)$, and experimental capacity normalized by geometric surface area $\left(Q_{1 \text { normal }}\right)$.

\begin{tabular}{|c|c|c|c|c|c|c|c|c|c|}
\hline Sample & $\begin{array}{c}\text { Oxide } \\
\text { content }^{\mathrm{a}}(\mathrm{wt} \%)\end{array}$ & $\begin{array}{c}Q_{1} \\
\left(\mathrm{~mA} \mathrm{~h}^{-1}\right)\end{array}$ & $\begin{array}{c}Q_{1 \text { oxide }}{ }^{\mathrm{b}} \\
\left(\mathrm{mA} \mathrm{h}^{-1}\right)\end{array}$ & $\begin{array}{c}S S A \\
\left(\mathrm{~m}^{2} \mathrm{~g}^{-1}\right)\end{array}$ & $\begin{array}{c}Q_{1 C C}{ }^{\mathrm{c}} \\
\left(\mathrm{mA} \mathrm{h}^{-1}\right)\end{array}$ & $\begin{array}{c}Q_{1 o x}{ }^{\mathrm{d}} \\
\left(\mathrm{mA} \mathrm{h}^{-1}\right)\end{array}$ & $\begin{array}{l}\mathrm{Mn} / \mathrm{Co} \\
\text { ratio }^{\mathrm{e}}\end{array}$ & $\begin{array}{c}Q_{1 \text { estimated }}^{\mathrm{f}} \\
\left(\mathrm{mA} \mathrm{h} \mathrm{g}^{-1}\right)\end{array}$ & $\begin{array}{c}Q_{1 \text { normal }^{\mathrm{g}}} \\
\left(\mathrm{mA} \mathrm{h} \mathrm{cm}^{-2}\right)\end{array}$ \\
\hline $\mathrm{CC}$ & - & 38 & - & 1100 & 38 & - & - & - & 0.39 \\
\hline $\mathrm{Mn}$ & 8.2 & 62 & 331 & 547 & 19 & 556 & - & - & 0.69 \\
\hline $\mathrm{Co}$ & 7.4 & 52 & 227 & 472 & 16 & 455 & - & - & 0.55 \\
\hline $\mathrm{MnCo} 50$ & 7.3 & 59 & - & 515 & 18 & - & $0.3 / 0.7$ & 54 & 0.64 \\
\hline $\mathrm{MnCo}$ & 8.8 & 52 & - & 446 & 15 & - & $0.1 / 0.9$ & 56 & 0.63 \\
\hline CoMn & 12 & 71 & - & 506 & 17 & - & $0.5 / 0.5$ & 67 & 0.87 \\
\hline Mn 3cy & 12.2 & 61 & 227 & - & - & - & - & - & 0.70 \\
\hline Mn 6cy & 12 & 60 & 221 & - & - & - & - & - & 0.66 \\
\hline Co 3cy & 14 & 49 & 117 & - & - & - & - & - & 0.60 \\
\hline Co 6cy & 17 & 51 & 114 & - & - & - & - & - & 0.66 \\
\hline
\end{tabular}

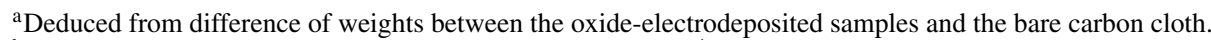

${ }^{\mathrm{b}}$ Estimated according to Eq. 3 in which $Q_{1 c c}=38 \mathrm{~mA} \cdot \mathrm{h} \cdot \mathrm{g}^{-1}$.

${ }^{\mathrm{c}}$ Estimated according to the specific capacity of bare CC $\left(38 \mathrm{~mA} \cdot \mathrm{h} \cdot \mathrm{g}^{-1}\right)$ and the specific surface area $(S S A)$ ascribed to the CC acting as substrate in each sample, i.e. $Q_{1 C C}=38 \cdot S S A / 1100$

${ }^{\mathrm{d}}$ Estimated according to Eq. 3 but taking the value of $Q_{1 c c}$ for each sample (sixth column).

${ }^{\mathrm{e}}$ Deduced from EDS-SEM measurements.

${ }^{\mathrm{f}}$ Estimated according to Eq. 4 in which $Q_{1 \text { cc }}=38 \mathrm{~mA} \cdot \mathrm{h} \cdot \mathrm{g}^{-1}, Q_{1 \text { Mn oxide }}=331 \mathrm{~mA} \cdot \mathrm{h} \cdot \mathrm{g}^{-1}$ and $Q_{1 \text { Co oxide }}=227 \mathrm{~mA} \cdot \mathrm{h} \cdot \mathrm{g}^{-1}$.

gEstimated according to $Q_{1 \text { normal }}=Q_{1}\left(\mathrm{~mA} \cdot \mathrm{h} \cdot \mathrm{g}^{-1}\right) \cdot A N E M\left(\mathrm{~g} \cdot \mathrm{cm}^{-2}\right)$; where $A N E M$ is the area-normalized electrode mass. 
specific capacity of $308 \mathrm{~mA} \cdot \mathrm{h} \cdot \mathrm{g}^{-1}$ for $\mathrm{MnO}_{2}$ and $304 \mathrm{~mA} \cdot \mathrm{h} \cdot \mathrm{g}^{-1}$ for $\mathrm{MnOOH}$ and (ii) the $Q_{1 \text { oxide }}$ value of the deposited Co oxide, of $227 \mathrm{~mA} \cdot \mathrm{h} \cdot \mathrm{g}^{-1}$, is intermediate between the theoretical specific capacity of $111 \mathrm{~mA} \cdot \mathrm{h} \cdot \mathrm{g}^{-1}$ for $\mathrm{Co}_{3} \mathrm{O}_{4}$ and the theoretical specific capacity of $288 \mathrm{~mA} \cdot \mathrm{h} \cdot \mathrm{g}^{-1}$ for $\mathrm{Co}(\mathrm{OH})_{2}$ or $291 \mathrm{~mA} \cdot \mathrm{h} \cdot \mathrm{g}^{-1}$ for $\mathrm{CoOOH}$.

If it is assumed that the deposited oxide covers the pores of the CC substrate inducing a decrease of the specific surface area (SSA), and hence a decrease of $Q_{1 C C}$, the values of $Q_{1 C C}$ can be estimated according to $Q_{1 C C}=38 \cdot S S A / 1100$, where $38 \mathrm{~mA} \cdot \mathrm{h} \cdot \mathrm{g}^{-1}$ is the specific capacity of a CC having $1100 \mathrm{~m}^{2} \mathrm{~g}^{-1}$ of specific surface area. The values of SSA and the deduced values of $Q_{1 C C}$ are shown in Table III. From these $Q_{1 C C}$ values it is possible to deduce the $Q_{1 \text { oxide }}$ values according to Eq. 3. For the Mn sample and also for the Co one having the oxide contents of 8.2 and $7.4 \mathrm{wt} \%$, respectively, the $Q_{1 \text { oxide }}$ value is $556 \mathrm{~mA} \cdot \mathrm{h} \cdot \mathrm{g}^{-1}$ for the deposited $\mathrm{Mn}$ oxide and $455 \mathrm{~mA} \cdot \mathrm{h} \cdot \mathrm{g}^{-1}$ for the deposited Co oxide. These specific capacities are higher than the theoretical values of $\mathrm{MnOOH}\left(304 \mathrm{~mA} \cdot \mathrm{h} \cdot \mathrm{g}^{-1}\right)$ or $\mathrm{MnO}_{2}\left(308 \mathrm{~mA} \cdot \mathrm{h} \cdot \mathrm{g}^{-1}\right)$ and also higher than the theoretical values of $\mathrm{Co}(\mathrm{OH})_{2}\left(288 \mathrm{~mA} \cdot \mathrm{h} \cdot \mathrm{g}^{-1}\right)$ or $\mathrm{CoOOH}\left(291 \mathrm{~mA} \cdot \mathrm{h} \cdot \mathrm{g}^{-1}\right)$. Hence, the hypothesis of the $Q_{1 C C}$ values deduced from the decrease of the specific surface area of CC is not experimentally supported by the results of Table III.

Owing to the limitation to get $Q_{1}$ values above $62 \mathrm{~mA} \cdot \mathrm{h} \cdot \mathrm{g}^{-1}$ for the samples having Mn oxide only and above $50 \mathrm{~mA} \cdot \mathrm{h} \cdot \mathrm{g}^{-1}$ for the samples having Co oxide only (see Figure 6), the samples MnCo50, $\mathrm{MnCo}$ and CoMn having the two oxides were prepared and studied. These samples look like a mixture of three components, the two deposited oxides and the carbon cloth, as studied by SEM and XPS. In electrodes having two components, e.g. $\mathrm{RuO}_{2} \cdot \mathrm{xH}_{2} \mathrm{O}$ as pseudocapacitor material and mesoporous carbon as double-layer capacitor material, the rule of mixtures worked for the specific capacitance of these composites. ${ }^{74}$ Our CC shows an average micropore size of 1.7 $\mathrm{nm}$, which is close to the beginning of the mesopore range, $2-50 \mathrm{~nm}$. So, the specific capacity of the electrodes MnCo50, MnCo and CoMn would hold the rule of mixtures in spite of the fact that they are made from one capacitor component and two battery components. To check this, the experimental $Q_{1}$ values of the three samples are compared with the values estimated according to the equation:

$$
Q_{1 \text { estimated }}=\left(m_{c c} \cdot Q_{1 c c}+m_{\mathrm{Mn}} \cdot Q_{1 \mathrm{Mn}}+m_{\mathrm{Co}} \cdot Q_{1 \mathrm{Co}}\right) / 100
$$

where $m_{\mathrm{cc}}, m_{\mathrm{Mn}}$ and $m_{\mathrm{Co}}$ stand for the weight in percentage of CC, Mn oxide and Co oxide, respectively; the parameters $Q_{1 \text { cc }}, Q_{1 \mathrm{Mn}}$ and $Q_{1 \text { co }}$ take the values 38,331 , and $227 \mathrm{~mA} \cdot \mathrm{h} \cdot \mathrm{g}^{-1}$, respectively. For the three oxide-deposited samples, the $Q_{\text {lestimated }}$ values agree with the experimental $Q_{1}$ ones within a difference of $5 \mathrm{~mA} \cdot \mathrm{h} \cdot \mathrm{g}^{-1}$, which corresponds to an error bar of 6-8\% (Table III). Therefore, the synergy of the two deposited oxides and the carbon cloth works according to Eq. 4. The experimental hold of Eq. 4 supports the choice of Eq. 3 to estimate the $Q_{1 \text { oxide }}$ value of the deposited Mn oxide or the deposited Co one in the samples having one oxide only. Comparing the three samples having the two oxides (Figure 6), the $Q_{1}$ value is higher for the CoMn sample than for the MnCo sample and the MnCo50 one; it can be explained by the higher content of the two oxides in the former sample and by the higher content of $\mathrm{Mn}$ oxide vs Co oxide in the former sample as compared to the other two samples (the deposited Mn oxide, with $331 \mathrm{~mA} \cdot \mathrm{h} \cdot \mathrm{g}^{-1}$, contributes more to the total capacity than the deposited Co oxide, with $\left.227 \mathrm{~mA} \cdot \mathrm{h} \cdot \mathrm{g}^{-1}\right)$. Comparing in Figure 6 the $Q_{1}$ value of the CoMn sample (with $6 \mathrm{wt} \%$ of Mn oxide and $6 \mathrm{wt} \%$ of Co oxide) with the $Q_{1}$ value of samples having similar oxide content, e.g. the $Q_{1}$ value of the Mn 3cy sample (with $12.2 \mathrm{wt} \%$ of Mn oxide) and the $Q_{1}$ value of Co 3cy sample (with $14 \mathrm{wt} \%$ of Co oxide), the higher $Q_{1}$ value found for the former sample is explained by the higher $Q_{\text {loxide }}$ value of the two deposited oxides in that sample (331 vs. $227 \mathrm{~mA} \cdot \mathrm{h} \cdot \mathrm{g}^{-1}$ for the deposited Mn oxide and 227 vs. $117 \mathrm{~mA} \cdot \mathrm{h} \cdot \mathrm{g}^{-1}$ for the deposited Co oxide).

Table III also shows the capacity normalized by the geometric surface area of each electrode. The normalized capacities are in the range $0.4-0.9 \mathrm{~mA} \cdot \mathrm{h} \cdot \mathrm{cm}^{-2}$ for all the samples. For the CoMn sample, the normalized capacity is 2.25 times the value of the bare $\mathrm{CC}$.

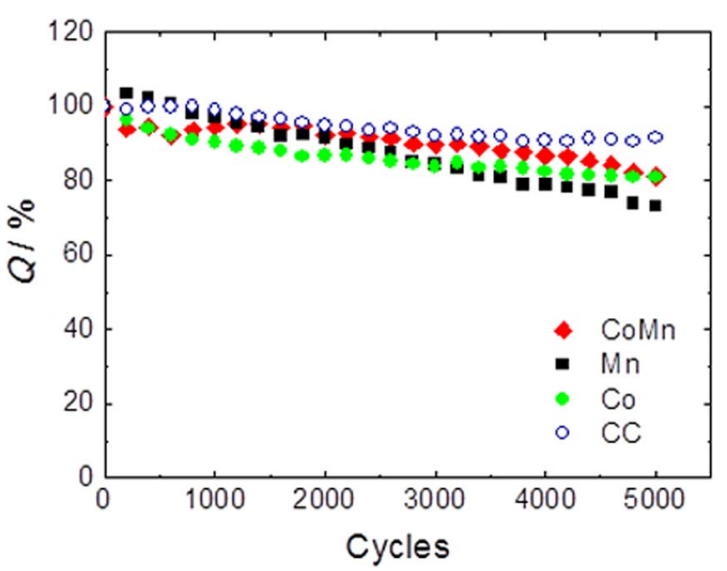

Figure 7. Variation of the specific capacity of the samples Mn, Co, CoMn and $\mathrm{CC}$ as a function of the number of charge/discharge cycles. The galvanostatic measurements were carried out at the current density of $26 \mathrm{~mA} \mathrm{~cm}^{-2}$.

Finally, the cycle life has been checked for the CC sample, the Mn sample, the Co sample and the CoMn one (Figure 7). These measurements were carried out in two-electrode cells. The cycle life is better for the bare CC sample than for the oxide-deposited samples. It agrees with the pure supercapacitor response of the former sample and the mix supercapacitor/battery response of the latter. After 5000 charge/discharge cycles, the specific capacity was $92 \%$ for the bare CC, $82 \%$ for the Co sample and the CoMn one and $73 \%$ for the Mn sample. The improvement of cyclability associated with the presence of Co oxide in the oxide-deposited samples agrees with that reported elsewhere. ${ }^{67,68}$

\section{Conclusions}

Flexible electrodes were obtained by potentiodynamic electrodeposition of $\mathrm{Mn}$ oxide and/or Co one on carbon cloth. The electrode flexibility is provided by the carbon cloth acting as scaffold or substrate. The electrodes prepared are binder free. Looking at the electrodes having the two oxides, their relative content depends on the manner the electrodeposition was carried out, either simultaneously or sequentially. In the latter case, the content of the two oxides also depends on which oxide was first electrodeposited. In all electrodes the two deposited oxides appear as aggregates. The aggregates of the Co oxide are more uniformly distributed on the carbon fibers than those of the Mn oxide. The aggregates are built up from connected flakes or sheets. The presence of voids between the flakes or sheets favors the access of the electrolyte to the interior of the deposited oxides and also to the surface of the carbon fibers.

The electrochemical response of the electrodes in $\mathrm{KOH}$ electrolyte combines the battery response of the two oxides with the supercapacitor response of the substrate. The electrodes can reach a specific capacity of $71 \mathrm{~mA} \cdot \mathrm{h} \cdot \mathrm{g}^{-1}$ and an area-normalized capacity of $0.9 \mathrm{~mA} \cdot \mathrm{h} \cdot \mathrm{cm}^{-2}$. The electrode capacity depends on the content of the oxide (or the two oxides) and the content of the carbon cloth according to the rule of mixtures. The deposited Mn oxide contributes more to the electrode capacity than the deposited Co oxide. At low current densities, the deposited oxides contribute to increase the electrode capacity (battery contribution plus supercapacitor one). At high current densities, the carbon cloth dominates the electrode capacity (supercapacitor contribution only). The cycle life is longer for the carbon cloth (supercapacitor response) than for the oxide-deposited electrodes (battery response plus supercapacitor one). The presence of Co oxide improves the cycle life of electrodes having Mn oxide.

\section{Acknowledgments}

Financial support from the project MAT2014-57687-R is gratefully acknowledged. We thank J.A. Diaz from Carbongen SA and 
R. Beneito from AIJU for providing the carbon cloth and also for helpful discussions.

\section{References}

1. H. Y. Lee and J. B. Goodenough, "Supercapacitor behavior with $\mathrm{KCl}$ electrolyte," J. Solid State Chem., 144, 220 (1999).

2. S.-C. Pang, M. A. Anderson, and T. W. Chapman, "Novel electrode materials for thin-film ultracapacitors: Comparison of electrochemical properties of sol-gel derived and electrodeposited manganese dioxide," J. Electrochem. Soc., 147(2), 444 (2000)

3. M. Toupin, T. Brousse, and D. Belanger, "Influence of microstructure on the charge storage properties of chemically synthesized manganese dioxiode," Chem. Mater. 14, 3946 (2002).

4. J. Jiang and A. Kucernak, "Electrochemical supercapacitor material based on manganese oxide: preparation and characterization," Electrochim. Acta, 47, 2381 (2002).

5. R. N. Reddy and R. G. Reddy, "Sol-gel $\mathrm{MnO}_{2}$ as an electrode material for electrochemical capacitors," J. Power Sources, 124, 330 (2003).

6. C. Xu, B. Li, H. Du, F. Kang, and Y. Zeng, "Electrochemical properties of nanosized hydrous manganese dioxide synthesized by a self-reacting microemulsion method," J. Power Sources, 180, 664 (2008).

7. E. Beaudrouet, A. Le Gal La Salle, and D. Guyomard, "Nanostructured manganese dioxides: Synthesis and properties as supercapacitor electrode materials," Electrochim. Acta, 54, 1240 (2009).

8. A. Yuan, X. Wang, Y. Wang, and J. Hu, "Textural and capacitive characteristics of $\mathrm{MnO}_{2}$ nanocrystals derived from a novel solid-reaction route," Electrochim. Acta, 54, 1021 (2009)

9. S. W. Donne, A. F. Hollenkamp, and B. C. Jones, "Structure, morphology and electrochemical behavior of manganese oxides prepared by controlled decomposition of permanganate," J. Power Sources, 195, 367 (2010).

10. Y. Yang and C. Huang, "Effect of synthetical conditions, morphology, and crystallographic structure of $\mathrm{MnO}_{2}$ on its electrochemical behavior," J. Solid State Electrochem., 14, 1293 (2010).

11. A. J. Roberts and R. C. T. Slade, "Controlled synthesis of $\varepsilon-\mathrm{MnO}_{2}$ and its application in hybrid supercapacitor devices," J. Mater. Chem., 20, 3221 (2010).

12. E. Raymundo-Piñero, V. Khomenko, E. Frackowiak, and F. Beguin, "Performance of manganese oxide/CNTs composites as electrode materials for electrochemical capacitors," J. Electrochem. Soc., 152(1), A229 (2005).

13. X. Dong, W. Shen, J. Gu, L. Xiong, Y. Zhu, H. Li, and J. Shi, " $\mathrm{MnO}_{2}$-embedded in mesoporous carbon wall structure for use as electrochemical capacitor," J. Phys. Chem. B, 110, 6015 (2006)

14. V. Subramanian, H. Zhu, and B. Wei, "Synthesis and electrochemical characterization of amorphous manganese oxide and single wall carbon nanotube composites as supercapacitor electrode materials," Electrochem. Commun., 8, 827 (2006).

15. A. E. Fischer, K. A. Pettigrew, D. R. Rolison, R. M. Stroud, and J. W. Long, "Incorporation of homogeneous, nanoscale $\mathrm{MnO} 2$ within ultraporous carbon structures via self-limiting electroless deposition: Implications for electrochemical capacitors,' Nano Lett., 7, 281 (2007).

16. X. Xie and L. Gao, "Characterization of a manganese dioxide/carbon nanotube composite fabricated using an in situ coating method," Carbon, 45, 2365 (2007).

17. C.-Y. Chen, T.-C. Cien, Y.-C. Chan, C.-K. Lin, and S.-C. Wang, "Pseudocapacitive properties of carbon nanotube/manganese oxide electrode deposited by electrophoretic deposition," Diamond Related Mater., 18, 482 (2009).

18. P. Staiti and F. Lufrano, "Study and optimization of manganese oxide-based electrodes for electrochemical supercapacitors," J. Power Sources, 187, 284 (2009).

19. L. L. Zhang, T. Wei, W. Wang, and X. S. Zhao, "Manganese oxide-carbon composite as supercapacitor electrode materials," Micropor. Mesopor. Mater, 123, 260 (2009)

20. G.-R. Li, Z.-P. Feng, Y.-N. ou, D. Wu, R. Fu, and Y.-X Tong, "Mesoporous $\mathrm{MnO}_{2}$ /carbon aerogel composites as promising electrode materials for high performance supercapacitors," Langmuir, 26(4), 2209 (2010).

21. A. Malak-Polaczyk, C. Matei-Ghimbeu, C. Vix-Guterl, and E. Frackowiak, "Carbon $/ \lambda-\mathrm{MnO}_{2}$ composites for supercapacitor electrodes," J. Solid State Electrochem., 183, 969 (2010).

22. X. Lang, A. Hirata, T. Fujita, and M. Chen, "Nanoporous metal/oxide hybrid electrodes for electrochemical supercapacitors," Nature Nanotechnology, 6(4), 232 (2011)

23. J.-G. Wang, Y. Yang, Z.-H. Huang, and F. Kang, "Effect of temperature on the pseudocapacitive behavior of freestanding $\mathrm{MnO}_{2} @$ carbon nanofibers composite electrodes in mild electrolyte," J. Power Sources, 224, 86 (2013).

24. M. J. Tadjer, M. A. Mastro, J. M. Rojo, A. Bosca, F. Calle, F. J. Kub, and C. R. Eddy $\mathrm{Jr}$, " $\mathrm{MnO}_{2}$-based electrochemical supercapacitors on flexible carbon substrates," J. Electronic Mater, 43(4), 1188 (2014).

25. D. Zhou, H. Lin, F. Zhang, H. Niu, L. Cui, Q. Wang, and F. Qu, "Freestanding $\mathrm{MnO}_{2}$ nanoflackes/porous carbon nanofibers for high-performance flexible supercapacitor electrodes," Electrochim. Acta, 161, 427 (2015).

26. A. Kozawa and J. F. Yeager, "The cathodic reduction mechanism of electrolytic manganese dioxide in alkaline electrolyte," J. Electrochem. Soc., 112(10), 959 (1965).

27. S. Rodrigues, N. Munichandraiah, and A. K. Shukla, "A cyclic voltammetric study of the kinetics and mechanism of electrodeposition of manganese dioxide," J. Appl. Electrochem., 28, 1235 (1998).

28. J.-K. Chang and W.-T. Tsai, "Material characterization and electrochemical performance of hydrous manganese oxide electrodes for use in electrochemical pseudocapacitors," J. Electrochem. Soc., 150(10), A1333 (2003)
29. M. S. Wu, "Electrochemical capacitance from manganese oxide nanowire structure synthesized by cyclic voltammetric electrodeposition," App. Phys. Lett., 87, 153102 (2005).

30. S. Chou, F. Cheng, and J. Chen, "Electrodeposition synthesis and electrochemical properties of nanostructured $\Upsilon-\mathrm{MnO}_{2}$ films," J. Power Sources, 162, 727 (2006)

31. H. Zang, G. Cao, Z. Wang, Y. Yang, Z. Shi, and Z. Gu, "Growth of manganese oxide nanoflowers on vertically-aligned carbon nanotube arrays for high rate electrochemical capacitive energy storage," Nano Lett., 8(9), 2664 (2008).

32. Z.-P. Feng, G.-R. Li, J.-H. Zhong, Z.-L. Wang, Y.-N. Ou, and Y.-X. Tong, " $\mathrm{MnO}_{2}$ multilayer nanosheet clusters evolved from monolayer nanoshhets and their predominant electrochemical properties," Electrochem. Commun., 11, 706 (2009).

33. B. Babakhani and D. G. Ivey, "Anodic deposition of manganese oxide electrodes with rod-like structures for application as electrochemical capacitors," J. Power Sources, 195, 2110 (2010).

34. Y.-C. Chen, Y.-K. Hsu, Y.-G. Lin, Y.-K. Lin, Y.-Y. Horng, L.-C. Chen, and K.-H. Chen, "Highly fexible supercapacitors with manganese oxide nanosheet/carbon cloth electrode," Electrochim. Acta, 56, 7124 (2011)

35. C. Zhu, S. Guo, Y. Fang, L. Han, E. Wang, and S. Dong, "One-step electrochemical approach to the synthesis of graphene/MnO2 nanowall hybrids," Nano Res., 4, 648 (2011).

36. M. Kundu and L. Liu, "Direct growth of mesoporous $\mathrm{MnO} 2$ nanosheet arrays on nickel foam current collectors for high performance pseudocapacitors," J. Power Sources, 243, 676 (2013).

37. C.-C. Wang, H.-C. Chen, and S.-Y. Lu, "Manganese oxide/graphene aerogel composites as an outstanding supercapacitor electrode material," Chem. Eur. J., 20, 517 (2014).

38. H. Ashassi-Sorkhabi, E. Asghari, and P. Lale Badakhshan, "Potentiostatic and cyclic voltammetric deposition of nanostructured manganese oxide for supercapacitor applications," Current App. Phys., 14, 187 (2014).

39. J. Yang, L. Lian, H. Ruan, F. Xie, and M. Wei, "Nanostructured porous $\mathrm{MnO}_{2}$ on $\mathrm{Ni}$ foam substrate with a high mass loading via a $\mathrm{CV}$ electrodeposition route for supercapacitor application," Electrochim. Acta, 136, 189 (2014).

40. S. Hassan, M. Suzuki, S. Mori, and A. Abd El-Moneim, " $\mathrm{MnO}_{2} /$ carbon nanowall electrode for future energy storage application: effect of carbon nanowall growth period and $\mathrm{MnO}_{2}$ mass loading," RSC Adv., 4, 20479 (2014).

41. S. Yang, K. Cheng, J. Huang, K. Ye, Y. Xu, D. Cao, X. Zhang, and G. Wang, "High capacitance $\mathrm{MnO}_{2}$ nanoflakes on performed $\mathrm{C} / \mathrm{TiO}_{2}$ shell/core nanowire arrays for electrochemical energy storage," Electrochim. Acta, 120, 416 (2014).

42. V. Srinivasan and J. W. Weidner, "An electrochemical route for making porous nickel oxide electrochemical capacitors," J. Electrochem. Soc., 114(8), L210 (1997).

43. C. Lin, J. A. Ritter, and B. N. Popov, "Characterization of sol-gel-derived cobalt oxide xerogels as electrochemical capacitors," J. Electrochem. Soc., 145(12), 4097 (1998).

44. T. Brousse, D. Belanger, and J. W. Long, "To be or not to be pseudocapacitive," J. Electrochem. Soc., 162, A5185 (2015).

45. V. R. Shinde, S. B. Mahadik, T. P. Gujar, and C. D. Lokhande, "Supercapacitive cobalt oxide $\left(\mathrm{Co}_{3} \mathrm{O}_{4}\right)$ thin films by spray pyrolysis," Appl. Surf. Sci., 252, 7487 (2006).

46. H.-K. Kim, T.-Y. Seong, J.-H. Lim, W. I. Cho, and Y. S. Yoon, "Electrochemical and structural properties of radio frequency sputtered cobalt oxide electrodes for thin-film supercapacitors," J. Power Sources, 102, 167 (2001).

47. L. Cao, M. Lu, and H.-L. Li, "Preparation of mesoporous nanocrystalline $\mathrm{Co}_{3} \mathrm{O}_{4}$ and its applicability of porosity to the formation of electrochemical capacitance," $J$. Electrochem. Soc., 152(5), A871 (2005).

48. S. Xiong, C. Yuan, X. Zhang, B. Xi, and Y. Qian, "Controllable synthesis of mesoporous $\mathrm{Co}_{3} \mathrm{O}_{4}$ nanostructures with tunable morphology for application in supercapacitors," Chem. Eur. J., 15, 5320 (2009).

49. L. Cui, J. Li, and X.-G. Zhang, "Preparation and properties of $\mathrm{Co}_{3} \mathrm{O}_{4}$ nanorods as supercapacitor material," J. Appl. Electrochem., 39, 1871 (2009).

50. G. Wang, X. Shen, J. Horvat, B. Wang, H. Liu, D. Wexler, and J. Yao, "Hydrothermal synthesis and optical, magnetic, and supercapacitance properties of nanoporous cobalt oxide nanoroads," J. Phys. Chem. C, 113, 4357 (2009).

51. Y. Gao, S. Chen, D. Cao, G. Wang, and J. Yin, "Electrochemical capacitance of $\mathrm{Co}_{3} \mathrm{O}_{4}$ nanowire arrays supported on nickel foam," J. Power Sources, 195, 1757 (2010).

52. J. Liu, J. Jiang, C. Cheng, H. Hongxing, J. Zhang, H. Gong, and H. J. Fan, " $\mathrm{Co}_{3} \mathrm{O}_{4}$ nanowire@ $\mathrm{MnO}_{2}$ ultrathin nanosheet core/shell arrays: A new class of highperformance pseudocapacitive materials," Adv. Mater., 23, 2076 (2011).

53. L. Wang, X. Liu, X. Wang, X. Yang, and L. Lu, "Electrochemical capacitance study on $\mathrm{Co}_{3} \mathrm{O}_{4}$ nanowires for supercapacitors application," J. Mater. Sci.: Mater Electron, 22, 601 (2011).

54. W.-J. Zhou, M.-W. Xu, D.-D. Zhao, C.-L. Xu, and H.-L. Li, "Electrodeposition and characterization of ordered mesoporous cobalt hydroxide films on different substrates for supercapacitors," Micropor. Mesopor. Mater., 117, 55 (2009).

55. J. B. Wu, Y. Lin, X. H. Xia, J. Y. Xu, and Q. Y. Shi, "Pseudocapacitive properties of electrodeposited porous nanowall $\mathrm{Co}_{3} \mathrm{O}_{4}$ film," Electrochim. Acta, 56, 7163 (2011)

56. S. G. Kandalkar, H.-M. Lee, H. Chae, and C.-K. Kim, "Structural, morphological and electrical characteristics of electrodeposited cobalt oxide electrode for supercapacitor applications," Mater. Res. Bull., 46, 48 (2011).

57. Y. F. Yuan, X. H. Xia, J. B. Wu, X. H. Huang, Y. B. Pei, J. L. Yang, and S. Y. Guo, "Hierarchically porous $\mathrm{Co}_{3} \mathrm{O}_{4}$ film with mesoporous walls prepared via liquid crystalline template for supercapacitor application," Electrochem. Commun., 13, 1123 (2011).

58. C.-W. Kung, H.-W. Chen, C.-Y. Lin, R. Vittal, and K.-C. Ho, "Synthesis of $\mathrm{Co}_{3} \mathrm{O}_{4}$ nanosheets via electrodeposition followed by ozone treatment and their application to high performance supercapacitors," J. Power Sources, 214, 91 (2012). 
59. M. Aghazadeh, "Electrochemical preparation and properties of nanostructured $\mathrm{Co}_{3} \mathrm{O}_{4}$ as supercapacitor material," J. Appl. Electrochem., 42, 89 (2012).

60. Y.-L. Wang, Y.-Q. Zhao, and C.-L. Xu, "May 3D nickel foam electrode be the promising choice for supercapacitors?," J. Solid State Electrochem., 16, 829 (2012).

61. F. S. Fedorov, J. Linnemann, K. Tschulik, L. Giebeler, M. Uhlemann, and A. Gebert, "Capacitance performance of cobalt hydroxide-based capacitors with utilization of near-neutral electrolytes," Electrochim. Acta, 90, 166 (2013).

62. A. J. Jagadale, V. S. Kumbhar, R. N. Bulakhe, and C. D. Lokhande, "Influence of electrodeposition modes on the supercapacitive performance of $\mathrm{Co}_{3} \mathrm{O}_{4}$ electrodes," Energy, 64, 234 (2014).

63. G. Nagaraju, Y. H. Ko, and J. S. Yu, "Tricobalt tetroxide nanoplate arrays on flexible conductive fabric substrate: Facile synthesis and application for electrochemical supercapacitors," J. Power Sources, 283, 251 (2015).

64. K. R. Prasad and N. Miura, "Electrochemically synthesized $\mathrm{MnO}_{2}$-based mixed oxides for high performance redox supercapacitors," Electrochem. Commun., 6, 1004 (2004).

65. P.-Y. Chuang and C.-C. Hu, "The electrochemical characteristics of binary manganese-cobalt oxides prepared by anodic deposition," Mater. Chem. Phys., 92, 138 (2005)

66. H. Zheng, F. Tang, M. Lim, A. Mukherji, X. Yan, L. Wang, and G. Q. (Max) Lu, "Multilayer films of cobalt oxyhydroxide nanowires/manganese oxide nanosheets for electrochemical capacitor," J. Power Sources, 195, 680 (2010).
67. B. Babakhani and D. Ivey, "Investigation of electrochemical behavior of Mn-Co doped oxide electrodes for electrochemical capacitors," Electrochim. Acta, 56, 4753 (2011).

68. G. Wang, W. Wang, Y. Zhao, G. Shao, T. Liu, and Z. Ma, "Pulsed electrodeposition of mesoporous cobalt-doped manganese dioxide as supercapacitor electrode material," Ionics, 20, 243 (2014).

69. J. M. Sieben, E. Morallon, and D. Cazorla-Amoros, "Flexible ruthenium oxideactivated carbon cloth composites prepared by simple electrodeposition methods," Energy, 58, 519 (2013).

70. P. Simon, Y. Gogotsi, and B. Dunn, "Where do batteries end and supercapacitors begin?" Science, 343, 1210 (2014).

71. M. Oku, K. Kirokawa, and S. Ikeda, "X-Ray Photoelectron Spectroscopy of Manganese-Oxygen Systems," J. Electron. Spectrosc. Relat. Phenom., 7, 465 (1975).

72. C. V. Schenck, J. G. Dillard, and J. W. Murray, "Surface Analysis and the Adsorption of Co(11) on Goethite," J. Colloid Interface Sci., 95, 398 (1983).

73. B. J. Tan, K. J. Klabunde, and P. M. A. Sherwood, "XPS studies of solvated metal atom dispersed (SMAD) catalysts. Evidence for layered cobalt-manganese particles on alumina and silica," J. Am. Chem. Soc., 113(3), 885 (1991).

74. F. Pico, E. Morales, J. A. Fernandez, T. A. Centeno, J. Ibañez, R. M. Rojas, J. M. Amarilla, and J. M. Rojo, "Ruthenium oxide/carbon composites with microporous or mesoporous carbon as support and prepared by two procedures. A comparative study as supercapacitor electrodes," Electrochim. Acta, 54, 2239 (2009). 